\title{
GROWTH AND PUBERTY IN THE COELIAC DISEASE OF THE CHILD
}

M. Bessahraoui, K. Bouziane Nedjadi, G. Boudraa, M. Touhami Service of Peadiatrics ' $C$ ' CHU Oran, Oran, Algeria

The aim of the present study was to evaluate growth, celiac disease (CD) adult height and age at menarche.

\section{Subjects and methods:}

1. Growth was assessed by: -Longitudinal study, compared with Sempé, Pédron subjects. -Semi longitudinal case-control study. Controls (eliac brothers and sisters).

2. Age at menarche was assessed by case-control study. Controls ( eliac sisters).

\section{Results:}

1. Growth was significantly more delayed in CD patients (103 girls,92 boys) than in Sempé, Pédron subjects. However, evident catch-up growth was noted between the 18 and 21 years age ( $103 \mathrm{CD}$ girls and $92 \mathrm{CD}$ boys CD).

2. The growth speed was less important during puberty compared to Sempé, Pédron subjects. After 18 age, our CD patients was contuned their growth in time where Sempé, Pédron subjects finished their growth.

3. When CD was associated with Diabete type 1, growth was significantly more delayed than in the CD isolated or diabetes patients isolated.

4. Semi-longitudinal study: The mean adult height was: $158,42 \pm 6,3 \mathrm{~cm}$ ( 269 women CD) vs $162,17 \pm 6,3$ $\mathrm{cm}(193$ controls $: \mathrm{p}<0,0001)$. The mean adult height was 170, $28 \pm 7,5 \mathrm{~cm}(194$ men CD) and 172, $53 \pm 6,8$ $\mathrm{cm}(200$ controls: $\mathrm{p}<0.09)$. 5.The mean age of menarche in $174 \mathrm{CD}$ was: $4,56 \pm 1,63$ years vs $13,74 \pm 1,36$ years in 174 controls $(\mathrm{p}<0,0001)$.

Conclusion: Growth, puberty and adult Height are delayed especially in the CD girls. Additional factors influencing growth, the auto immuns diseases associated. 